\title{
Ethamsylate protects against the carbon tetrachloride-induced liver damage in rats
}

\begin{abstract}
Ethamsylate is a synthetic haemostatic drug used for controlling capillary bleeding. In this study, the effect of ethamsylate on liver injury induced by acute carbon tetrachloride $\left(\mathrm{CCl}_{4}\right)$ administration in rats was investigated. Ethamsylate $(45,90$ or $180 \mathrm{mg} / \mathrm{kg}$ ) was given once daily orally simultaneously with $\mathrm{CCl}_{4}$ and continued for 1 week thereafter. The extent of liver damage was determined by measuring serum activities of alanine aminotransferase (ALT), aspartate aminotransferase (AST), and alkaline phosphatase (ALP) as well as by liver histopathology. Ethamsylate given at the above doses conferred significant hepatic protection against the $\mathrm{CCl}_{-}$-induced hepatotoxicity. It reduced serum ALT activities by $44.8 \%-70.9 \%$, AST by $46.1 \%-51.4 \%$, and ALP by $30.7 \%-48.5 \%$, respectively, compared to the $\mathrm{CCl}_{4}$ control group. Ethamsylate given at $90 \mathrm{mg} / \mathrm{kg}$ to $\mathrm{CCl}_{4}$-treated rats resulted in the preservation of the normal architecture of the liver tissue and no lymphocytic infiltration. These data indicate a beneficial effect for ethamsylate in the $\mathrm{CCl}_{4}$ model of hepatotoxicity.
\end{abstract}

Keywords: ethamsylate, silymarin, carbon tetrachloride, liver enzymes, alanine aminotransferase, aspartate aminotransferase, alkaline phosphatase

\author{
Volume 4 Issue 3 - 2017
}

\author{
Omar ME Abdel-Salam,' Nermeen M \\ Shaffie, ${ }^{2}$ Amany A Sleem ${ }^{3}$ \\ 'Department of Toxicology and Narcotics, National Research \\ Centre, Egypt \\ 2Department of Pathology, National Research Centre, Egypt \\ ${ }^{3}$ Department of Pharmacology, National Research Centre, Egypt
}

Correspondence:Omar ME Abdel-Salam, Department of Toxicology and Narcotics, National Research Centre, Tahrir St., I 23 I I, Dokki, Cairo, Egypt, Email omasalam@hotmail.com

Received: October 31, 2016 | Published: April 10, 2017

\section{Introduction}

Ethamsylate (diethylammonium 1 , 4-dihydroxy-3benzenesulphonate) is a synthetic haemostatic drug used to reduce bleeding in conditions such as menorrhagia ${ }^{1}$ and after transurethral resection for benign enlargement of the prostate. ${ }^{2}$ The agent has also been used to reduce the risk of cerebral haemorrhage in premature infants, but controversial data have been reported. ${ }^{3,4}$ In healthy humans receiving aspirin, ethamsylate decreased the bleeding time and blood loss. ${ }^{5}$ Ethamsylate appears to ensure haemostasis by increasing platelet-leukocyte aggregates. ${ }^{6}$ The drug also exhibited other important pharmacological actions, scavenging hydroxyl radicals, ${ }^{7}$ inhibiting prostaglandin synthesis, ${ }^{8}$ decreasing inflammation ${ }^{9}$ and decreasing vascular peritoneal permeabilization due to arachidonate.

In light of the above data and in view of the wide use of ethamsylate to control capillary bleeding, it looked pertinent to investigate the effect of the drug on the development of liver injury. The carbon tetrachloride $\left(\mathrm{CCl}_{4}\right)$ model of hepatotoxicity is used for this purpose. This industrial solvent is widely used to cause acute hepatic injury with centrilobular necrosis in rodents. Moreover, its long-term administration is associated with the development of liver cirrhosis and ascites. It is thus used to investigate potential therapeutic agents. ${ }^{10}$ The development of liver injury is largely ascribed to the formation of the trichloromethyl radical, $\mathrm{CCl}_{3}$ and the ensuing oxidative cellular damage, ${ }^{11}$ although vascular, ${ }^{12}$ and inflammatory ${ }^{13}$ mechanisms are also involved.

\section{Materials and method}

\section{Animals}

Adult Sprague-Dawley rats of either sex, weighing 130-150g were used in this study. Rats were fed with standard laboratory chow and water Ad libitum. Animal procedures were performed in accordance with the Ethics Committee of the National Research Centre and followed the recommendations of the National Institutes of Health Guide for Care and Use of Laboratory Animals (Publication No. 8523, revised 1985).

\section{Drugs and chemicals}

Carbon tetrachloride $\left(\mathrm{CCl}_{4}\right)$ (BDH Chemicals, UK), and ethamsylate (MINAPHARM Pharmaceuticals, Egypt) were used. The doses for rats used were based upon the human dose after conversion to that of rat according to Paget and Barnes conversion tables. ${ }^{14}$

\section{The $\mathrm{CCl}_{4}$ model of acute hepatic damage}

The rats were divided into 5 equal groups (six rats each). Groups 1-4 received $\mathrm{CCl}_{4}$ in olive oil $(1: 1, \mathrm{vol} / \mathrm{vol})$ at a dose of $2.8 \mathrm{ml} / \mathrm{kg}$ by gavage. Starting on the first day of $\mathrm{CCl}_{4}$, rats were also treated with ethamsylate $(45,90$ or $180 \mathrm{mg} / \mathrm{kg})$ once daily orally for one week. The fifth group of rats was treated with the vehicle (olive oil) at $2.8 \mathrm{ml} / \mathrm{kg}$ (no $\mathrm{CCl}_{4}$ ). Rats had free access to food and drinking water during the study.

\section{Biochemical assessment}

At the end of the study, blood samples were obtained from the retro-orbital venous plexus, under light ether anaesthesia. Alanine aminotransferase (ALT), aspartate aminotransferase (AST), and alkaline phosphatase (ALP) activities in serum were measured using commercially available kits (Biodiagnostic, Egypt).

\section{Histopathology}

After the end of the treatment period, rats were killed, the liver of different groups was removed, fixed in $10 \%$ formalin and $5 \mu \mathrm{m}$ thick paraffin sections were stained with haematoxylin and eosin (H\&E) and examined under the light microscope.

\section{Statistical analysis}

Data are expressed as means \pm SE. Multiple group comparisons were performed by ANOVA followed by Duncan's multiple range test $\mathrm{P}<0.05$ was considered statistically significant.

\section{Results}

\section{Effect of ethamsylate on serum enzyme activities}

Rats treated with $\mathrm{CCl}_{4}$ exhibited markedly increased activities of 
the liver enzymes ALT, AST, and ALP in plasma. Significant increase in ALT by $275.8 \%(71.4 \pm 3.6$ vs. $19.0 \pm 1.0 \mathrm{U} / \mathrm{L})$, AST by $105.8 \%$ $(262.8 \pm 13.0$ vs. $127.7 \pm 8.4 \mathrm{U} / \mathrm{L})$ and ALP by $96.0 \%(519.9 \pm 23.4$ vs. $265.3 \pm 15.6 \mathrm{U} / \mathrm{L}$ ) were observed after the administration of $\mathrm{CCl}_{4}$ compared with the saline control group. Ethamsylate given at the time of $\mathrm{CCl}_{4}$ administration at doses of 45,90 or $180 \mathrm{mg} / \mathrm{kg}$ caused dosedependent reduction of raised ALT by $44.8 \%, 61.1 \%$, and $70.9 \%$, respectively. Meanwhile, AST decreased by $46.1 \%, 46.3 \%$ and $51.4 \%$ and ALP by $30.7 \%, 36.3 \%$, and $48.5 \%$, respectively (Figure 1-3).

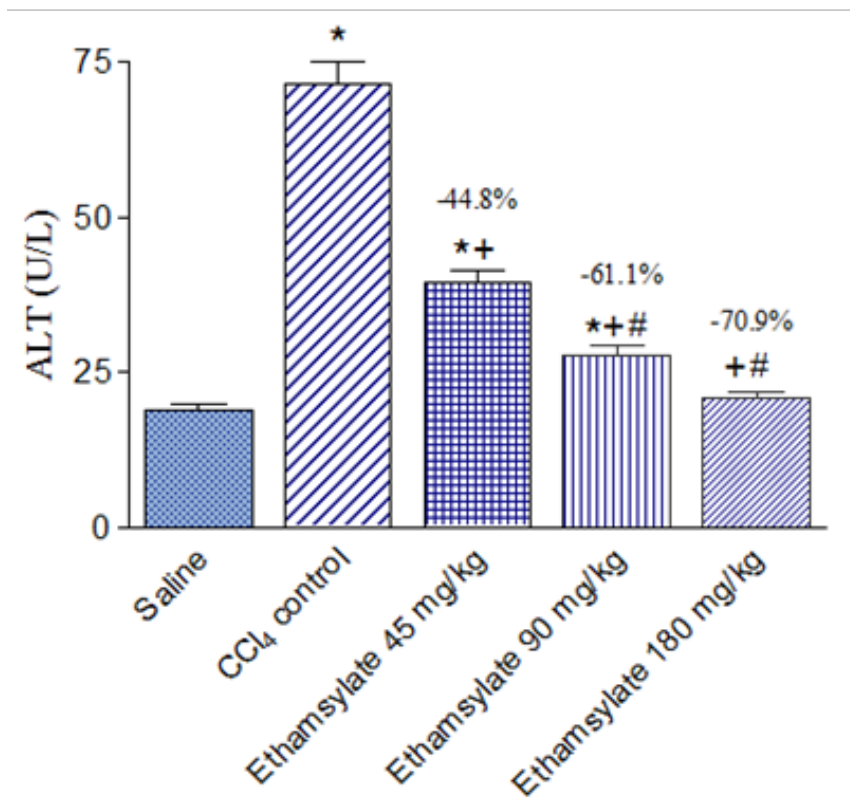

Figure I Effect of ethamsylate on serum ALT activity in $\mathrm{CCl}_{4}$ intoxicated rats. $* p<0.05$ vs. saline group. $+p<0.05$ vs. $\mathrm{CCl}_{4}$ control group. $\# p<0.05$ vs. ethamsylate $45 \mathrm{mg} / \mathrm{kg}$ treated group. The percentage change from the $\mathrm{CCl}_{4}$ control group is indicated on the figure.

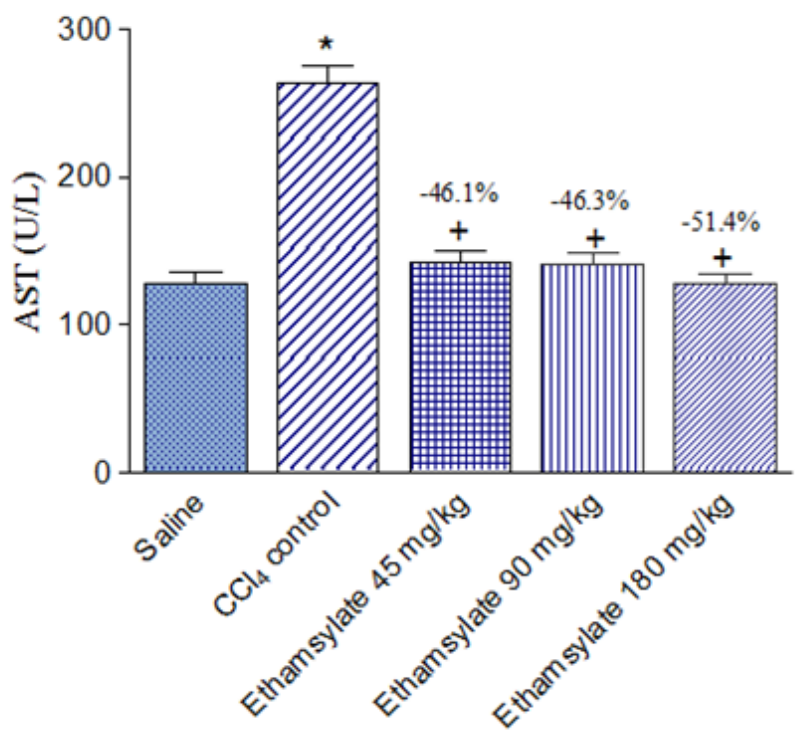

Figure 2 Effect of ethamsylate on serum AST activity in $\mathrm{CCl}_{4}$ intoxicated rats. ${ }^{*}<0.05$ vs. saline group. $+p<0.05$ vs. $\mathrm{CCl}_{4}$ control group. The percentage change from the $\mathrm{CCl}_{4}$ control group is indicated on the figure.

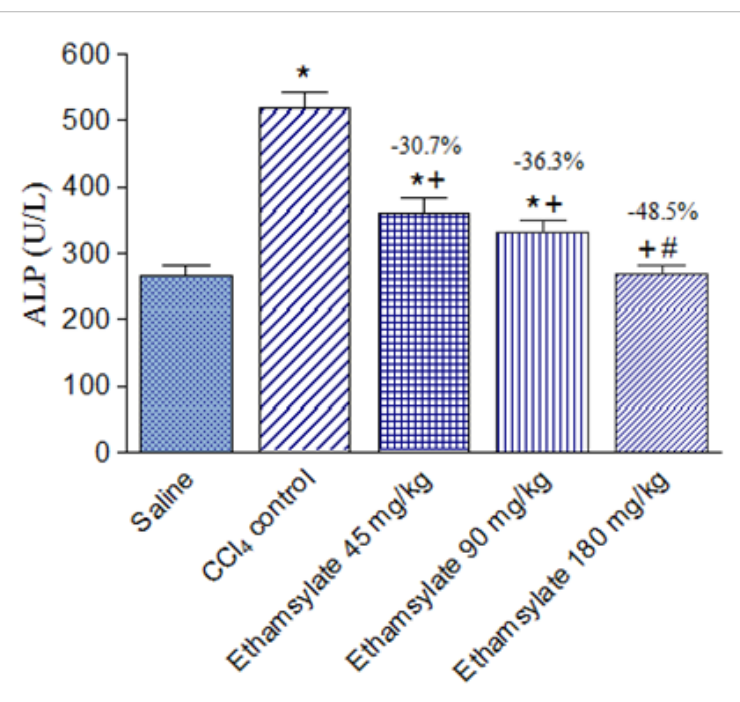

Figure 3 Effect of ethamsylate on serum ALP activity in $\mathrm{CCl}_{4}$ intoxicated rats. ${ }^{*}<<0.05$ vs. saline group. $+p<0.05$ vs. $C \mathrm{Cl}_{4}$ control group. $\# p<0.05$ vs. ethamsylate $45 \mathrm{mg} / \mathrm{kg}$ or $90 \mathrm{mg} / \mathrm{kg}$ treated group. The percentage change from the $\mathrm{CCl}_{4}$ control group is indicated on the figure.

\section{Effect of ethamsylate on $\mathrm{CCl}_{4^{-}}$induced histopathological changes}

Carbon tetrachloride caused marked damage to hepatic tissue in the form of severe dilatation of the portal tract vessels and central veins. There was also fibrosis that extended from a portal tract to another and dilatation of blood sinusoids (Figure 4). The administration of ethamsylate reduced the damaging effect of $\mathrm{CCl}_{4}$ in a dose- dependent manner. Minimal protection was observed with ethamsylate at $45 \mathrm{mg} / \mathrm{kg}$ as fibrosis with cellular infiltration was still observed, and hepatocytes still had pyknotic nuclei (Figure 5A) (Figure 5B). Ethamsylate given at $90 \mathrm{mg} / \mathrm{kg}$ caused obvious reduction of fibrosis and cellular infiltration with preservation of liver tissue architecture (Figure 5C) (Figure 5D). Ethamsylate given at $180 \mathrm{mg} / \mathrm{kg}$ afforded marked protection. The liver tissue has regained its normal structure except for very slight cellular infiltration around central veins being seen Figure 5E \& 5F.

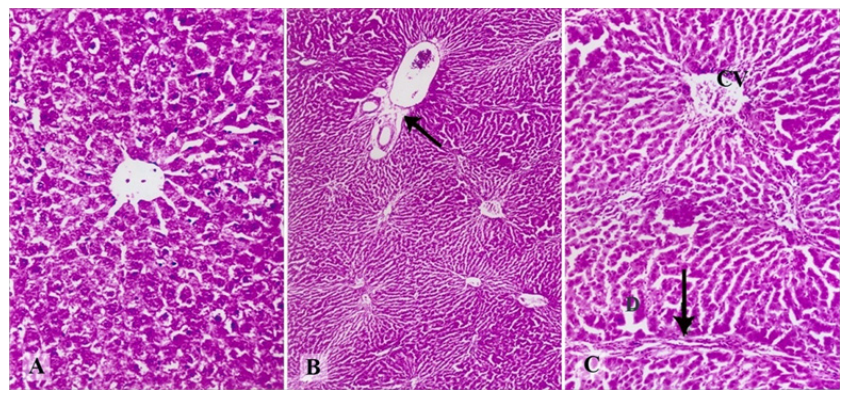

Figure $4 \mathrm{~A}$ photomicrograph of a section of liver tissue from a rat treated with

A. Saline showing the normal hepatic architecture.

B. $\mathrm{CCl}_{4}$ showing the presence of severe dilatation of the portal tract vessels (arrow) and mild dilatation with congestion of central veins.

C. A magnified photomicrograph from the previous section showing fibrosis extending from a portal tract to another (arrow), mild dilatation with congestion in the central vein $(C)$, and dilatation of blood sinusoids (D) (Hx \& E X200, 50 \& 100$)$. 


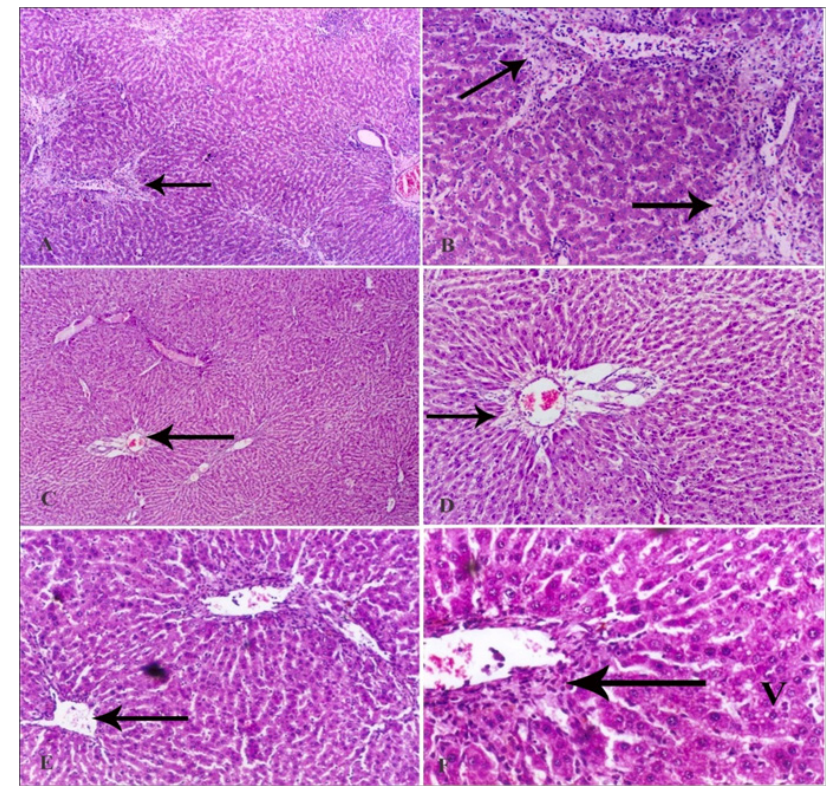

Figure $5 \mathrm{~A}$ photomicrograph of a section of the liver tissue from a rat treated with

A. $\mathrm{CCl}_{4}$ and $45 \mathrm{mg} / \mathrm{kg}$ ethamsylate showing dilatation and congestion of the portal tract vessels. Obvious fibrosis with lymphocytic infiltration is seen around the central veins which were also dilated and congested with blood (arrow).

B. A magnified photomicrograph for the previous section showing extensive fibrosis around a central vein with lymphocytic infiltration (arrow). The fibrous tissue extends within the parenchyma of the liver carrying lymphocytes and red blood cells. Many of the hepatocytes show small dense nuclei. Blood sinusoids are slightly dilated with increased number of Kupffer cells.

C. $\mathrm{CCl}_{4}+90 \mathrm{mg} / \mathrm{kg}$ ethamsylate showing mild dilatation with congestion in the portal vein (arrow), and in some central veins. No lymphocytic infiltration is seen and the normal architecture of the liver tissue is somehow preserved.

D. A magnified photomicrograph for the previous section showing mild dilatation of the portal vein whose endothelium is still intact. Fibrosis around the portal vein (arrow) is observed. Signs of edema appear in the parenchyma of the liver in the form of dilatation of blood sinusoids. Most of the hepatocytes are still showing small dense nuclei.

E. $\mathrm{CCl}_{4}+180 \mathrm{mg} / \mathrm{kg}$ ethamsylate showing preservation of the normal architecture of liver tissue and nearly normal-sized central veins (arrow).

F. A magnified photomicrograph for the previous section showing slight cellular infiltration around the central vein (arrow). Most of the hepatocytes appear normal with eosinophilic cytoplasm and large vesicular nuclei, while

a few of them suffer from vacuolar degeneration (V).

\section{Discussion}

The findings in the present study provide the first evidence for a protective effect for ethamsylate in the $\mathrm{CCl}_{4}$ model of hepatotoxicity. The leakage of liver enzymes into the plasma was decreased in a dose-dependent manner. The decrease in serum liver enzymes by ethamsylate clearly reflects a lower degree of liver damage. There was also histological evidence of decreased extent of liver damage, with the highest dose of ethamsylate tested restoring the normal hepatic architecture.

The $\mathrm{CCl}_{4}$-induced hepatotoxicity is due in large part to the oxidative modification of cellular biomolecules (nucleic acids, proteins, lipids). This is due to the formation of the trichloromethyl radical, $\mathrm{CCl}_{3}$ by the action of the cytochrome $\mathrm{P} 450$ oxygenase system. This free radical is capable of causing lipid peroxidation of the cell membrane. Moreover, in presence of molecular oxygen, $\mathrm{CCl}_{3}$ forms a highly reactive and short-lived species that is trichloromethylperoxy radical $\mathrm{CCl}_{3} \mathrm{OO} .{ }^{11}$ Carbon tetrachloride thus depletes cellular antioxidant molecules like reduced glutathione..$^{15}$ Ethamsylate showed antioxidant properties being particularly active against hydroxyl radicals $(\mathrm{OH} \bullet)$ but not against nitric oxide radicals. ${ }^{7}$ It is likely, however, that liver injury due to $\mathrm{CCl}_{4}$ is not only caused by the oxidative insult of $\mathrm{CCl}_{3}$ and $\mathrm{CCl}_{3} \mathrm{OO}$ but also involves other factors such as vascular perturbation which add to the initial oxidative insult. In this context, it has been shown chemical sympathectomy using 6-hydroxydopamine increased hepatic blood flow and decreased liver damage caused by $\mathrm{CCl}_{4}$ in rodents. ${ }^{12,13}$

The mechanism by which ethamsylate controls bleeding is not yet explained but the drug has been shown to act by improving platelet adhesiveness and restoring capillary resistance. ${ }^{16}$ In damaged blood vessels, ethamsylate which binds to the plasma membrane of leukocytes increases the expression of the P-selectin glycoprotein ligand and promotes leukocyte-platelet aggregation. ${ }^{6}$ The abovepostulated mechanisms appear to be of particular relevance to the protective action of ethamsylate against $\mathrm{CCl}_{4}$-mediated liver injury. The main physiological function of platelets is to ensure haemostasis by adhering to the sub endothelial surface of injured blood vessels forming the platelet plug. ${ }^{17}$ This anucleated blood cells store and release serotonin, a potent vasoconstrictor. Platelets also store fibrinogen, P-selectin, ATP, ADP, growth factors such as hepatocyte growth factor, vascular endothelial growth factor, platelet-derived growth factor, transforming growth factor-beta and others. ${ }^{18,19}$ Studies have indicated an important role for platelets both in the development of liver injury and also in hepatoprotection and liver regeneration. ${ }^{20-29}$ Following different forms of liver injury, platelets are recruited to the liver, adhere to endothelial lining, and cause leukocyte accumulation, sinusoidal flow disturbances ${ }^{20-22}$ and even apoptosis of sinusoidal endothelial cells..$^{20}$ Adherent platelets can also release serotonin, markedly impair sinusoidal microcirculation, and decrease $\mathrm{O}_{2}$ tension. ${ }^{23}$ These actions of platelets are likely to result in exacerbation of the toxicant-induced liver damage such as that caused by $\mathrm{CCl}_{4}$. Serotonin released from platelet has also been involved in liver injury after hepatic ischemia. ${ }^{24,25}$ In other circumstances such as extensive hepatectomy, inducing thrombocytosis prevented the development of acute liver injury. ${ }^{26}$ Platelets were also proved crucial to liver regeneration and this action is mostly a serotonin-mediated one. ${ }^{27,28}$ Moreover, the release of hepatocyte growth factor from platelets is suggested to help in liver repair and sinusoidal restoration following $\mathrm{CCl}_{4}$-induced liver injury in mice. ${ }^{29}$ Platelets, therefore, might have differing effects on the development of liver injury depending on the nature of the insult and the underlying pathomechanism(s) involved. Ethamsylate increases the membrane expression of the adhesion molecule P-selectin in platelets and causes platelet adhesiveness, ${ }^{30}$ suggesting a role for the latter in the protective effects of ethamsylate observed in this study. The drug has been shown to maintain pancreatic blood flow in acute canine necrotizing pancreatitis. ${ }^{31}$ It is thus possible that the ethamsylate protects the liver via maintaining blood flow. 


\section{Conclusion}

In summary, the present study describes for the first time a protective effect for the haemostatic drug ethamsylate in the $\mathrm{CCl}_{4}$ model of hepatotoxicity. It is suggested that ethamsylate decreases liver injury by antioxidant action as well as by virtue of an action on platelet adhesiveness or microvascular blood flow.

\section{Acknowledgements}

None.

\section{Conflict of interest}

Author declares that there is no conflict of interest.

\section{References}

1. Chamberlain G, Freeman R, Price F, et al. A comparative study of ethamsylate and mefenamic acid in dysfunctional uterine bleeding. $\mathrm{Br} J$ Obstet Gynaecol. 1991;98(7):707-711.

2. Symes DM, Offen DN, Lyttle JA, et al. The effect of dicynene on blood loss during and after transurethral resection of the prostate. $\mathrm{Br} J$ Urol. 1975;47(2):203-207.

3. Chen JY. Ethamsylate in the prevention of periventricular-intraventricular hemorrhage in premature infants. $J$ Formos Med Assoc. 1993;92(10):889-893

4. Elbourne D, Ayers S, Dellagrammaticas H, et al. EC Ethamsylate Trial Group. Randomized controlled trial of prophylactic etamsylate: follow up at 2years of age. Arch Dis Child Fetal Neonatal Ed. 2001;84(3):F183F187.

5. Hutton RA, Wickham EA, Reed JV, et al. Studies on the action of ethamsylate (Dicynene) on haemostasis. Thromb Haemost. 1986;56(1):6-8.

6. Hernandez MR, Alvarez-Guerra M, Escolar G, et al. The hemostatic agent ethamsylate promotes platelet/leukocyte aggregate formation in a model of vascular injury. Fundam Clin Pharmacol. 2004;18(4):423-430.

7. Hannaert P, Alvarez-Guerra M, Hider H, et al. Vascular permeabilization by intravenous arachidonate in the rat peritoneal cavity: antagonism by ethamsylate. Eur J Pharmacol. 2003;466(1-2):207-212.

8. Kovacs L, Falkay G. Etamsylate as inhibitor of prostaglandin biosynthesis in pregnant human myometrium in vitro. Experientia. 1981;37(11):1182-1183.

9. Gard PR, Trigger DJ. Effect of ethamsylate on carrageenan-induced rat paw oedema: a comparison with indomethacin. Clin Exp Pharmacol Physiol. 1990;17(12):821-827.

10. Murielin P. Some experimental models of liver damage. In: Sahu SC, editor. Hepatotoxicity: From Genomics to in vitro and in vivo Models. Chichester, UK: John Wiley and Sons Ltd; 2007. p. 119-137.

11. Weber LW, Boll M, Stampfl A. Hepatotoxicity and mechanism of action of haloalkanes: carbon tetrachloride as a toxicological model. Crit Rev Toxicol. 2003;33(2):105-136.

12. Hsu CT, Schichijo K, Ito M, et al. The effect of chemical sympathectomy on acute liver injury induced by carbon tetrachloride in spontaneously hypertensive rats. J Auton Nerv Syst. 1993;43(2):91-96.

13. Lin JC, Peng YJ, Wang SY, et al. Role of the sympathetic nervous system in carbon tetrachloride-induced hepatotoxicity and systemic inflammation. PLoS One. 2015;10(3): 0121365.
14. Paget GE, Barnes JM. Toxicity testing. In: Laurence DR, Bacharach AL, editors. Evaluation of drug activities pharmacometics. Academic, London, UK; 1964. p. 1-135.

15. Nishida K, Ohta Y, Kongo M, et al. Response of endogenous reduced glutathione through hepatic glutathione redox cycle to enhancement of hepatic lipid peroxidation with the development of acute liver injury in mice intoxicated with carbon tetrachloride. Res Commun Mol Pathol Pharmacol. 1996;93(2):198-218.

16. Vinazzer H. Clinical and experimental studies on the action of ethamsylate on haemostasis and on platelet functions. Thromb Res. 1980;19(6):783-791.

17. Jurk K, Kehrel BE. Platelets: physiology and biochemistry. Semin Thromb Hemost. 2005;31(4):381-392.

18. Gawaz M, Langer H, May AE. Platelets in inflammation and atherogenesis. J Clin Invest. 2005;115(12):3378-3384.

19. Kurokawa T, Zheng YW, Ohkohchi N. Novel functions of platelets in the liver. J Gastroenterol Hepatol. 2016;31(4):745-751.

20. Sindram D, Porte RJ, Hoffman MR, et al. Platelets induces sinusoidal endothelial cell apoptosis upon reperfusion of the cold ischemic rat liver. Gastroenterology. 2000;118(1):183-191.

21. Nakano Y, Kondo T, Matsuo R, et al. Platelet dynamics in the early phase of postischemic liver in vivo. J Surg Res. 2008;149(2):192-198.

22. Laschke MW, Dold S, Menger, et al. Platelet dependent accumulation of leukocytes in sinusoids mediates hepatocellular damage in bile duct ligation-induced cholestasis. Br J Pharmacol. 2008;153(1):148-156.

23. Lang PA, Contaldo C, Georgiev P, et al. Aggravation of viral hepatitis by platelet derived serotonin. Nat Med. 2008;14(7):756-761.

24. Khandoga A, Biberthaler P, Enders G, et al. Platelet adhesion mediated by fibrinogen-intercelllular adhesion molecule-1 binding induces tissue injury in the postischemic liver in vivo. Transplantation 2002;74(5):681-688

25. Murata R, Hamada N, Nakamura N, et al. Serotonin activity and liver dysfunction following hepatic ischemia and reperfusion. In Vivo. 2003;17(6):567-572

26. Hisakura K, Murata S, Fukunaga K, et al. Platelets prevent acute liver damage after extended hepatectomy in pigs. $J$ Hepatobiliary Pancreat Sci. 2010;17(6):855-864.

27. Lesurtel M, Graf R, Aleil B, et al. Platelet-derived serotonin mediates liver regeneration. Science. 2006;312(5770):104-107.

28. Shimabukuro R, Kawanaka H, Tomikawa M, et al. Effect of thrombopoietin on platelet counts and liver regeneration after partial hepatectomy in a rat model. Surg Today. 2009;39(12):1054-1059.

29. Minamino T, Ito Y, Ohkubo H, et al. Adhesion of platelets through thromboxane $\mathrm{A}_{2}$ receptor signaling facilitates liver repair during acute chemical-induced hepatotoxicity. Life Sci. 2015;132:85-92.

30. Alvarez-Guerra M, Hernandez MR, Escolar G, et al. The hemostatic agent ethamsylate enhances P-selectin membrane expression in human platelets and cultured endothelial cells. Thromb Res. 2002;107(6):329-335.

31. Wells AD, Schenk WG. Beneficial effect of ethamsylate on the relative blood flow of the pancreas in acute canine necrotizing pancreatitis. Surg Gynecol Obstet. 1982;155(5):673-678. 